\title{
Long-Term Effect of Dietary Fiber and Fat Intake on Japanese Colon Cancer Mortality
}

\author{
Keisuke Tsuji, ${ }^{1}$ Emiko Harashima, ${ }^{2}$ Yasue NaKagawa, ${ }^{2}$ Gunpei Urata ${ }^{2}$ \\ and Masuo ShIRATAKA ${ }^{3}$ \\ ' Division of Applied Food Research, National Institute of Health and Nutrition, \\ Shinjuku, Tokyo 162, Japan \\ ${ }^{2}$ Department of Food and Health Sciences, Faculty of Human Life Sciences, Fissen Women's University, \\ Hino, Tokyo 191, Japan \\ ${ }^{3}$ School of Medicine, Kitasato University, Sagamihara, Kanagawa 228, Japan
}

(Received May 26, 1996; Accepted for publication, July 15, 1996)

\begin{abstract}
The daily intake of total dietary fiber (TDF) was evaluated from data collected by the National Nutrition Survey in Japan over a period of 41 years since 1947. The interrelationships between dietary fiber, other nutrient intake and the mortality from colon cancer (MCC) were determined by a simple correlation coefficient and a time-series correlation coefficient. TDF intake per capita decreased rapidly from $27.4 \mathrm{~g}$ in 1947 to $15.8 \mathrm{~g}$ in 1963 , and subsequently decreased at a lesser rate to $15.3 \mathrm{~g}$ in 1987. The interrelationship between MCC and TDF intake could be represented by two linear regression lines, with similar findings also being observed for fat, fat energy ratio and fat/TDF. MCC has increased rapidly since the daily intake of TDF dropped to less than $18 \mathrm{~g}$. A time-series analysis indicates that MCC has a significantly positive maximum correlation with the intake of total fat and with the fat energy ratio after a 16-year delay. MCC was negatively correlated with TDF after a 15-27 year delay, the maximum correlation existing with a 24-year lag $(r=-0.918)$. Fat/TDF showed the most striking correlation with MCC with a 16-year lag $(r=$ -0.994) among all the parameters. It is suggested that the cause of increased MCC in Japan is positively related to the increased intake of fat. In addition, the decrease in TDF intake has accelerated MCC after a delay of 24 years. The importance of fat/ TDF as a nutritional criterion for the incidence of colon cancer needs to be better recognized.
\end{abstract}

Key words: total dietary fiber; fat; fat energy ratio; fat/total dietary fiber; colon cancer crude mortality

Dietary habits have dramatically changed in Japan since the Second World War. In addition, the death rate due to colon cancer within Japan has increased rapidly year by year (11). Japanese migrants to the United States show a higher mortality from colon cancer (MCC) than Japanese in Japan $(8,20)$. From the findings of these studies, the rapid increase of colon cancer has been due to environmental changes, especially nutrition, rather than heredity. The relationship between dietary fat and the risk of colon cancer has been suggested from the results of epidemiological studies $(3,7,12,23)$. Higher fat intake increases the biosynthesis and leaching of bile acids to the large intestine, as well as the growth of colon bacteria capable of converting primary bile acids to carcinogenic substances (10, 19). From this relationship, colon bacteria may 
have an important role in cancer. Dietary fiber is able to influence not only stool bulk, but also intestinal bacterial metabolism $(2,18)$. Fiber, bile acids and colon bacteria are interrelated as an ecosystem in the large intestine. These facts suggest that dietary fiber may also influence colon cancer risk.

The Ministry of Health and Welfare in Japan has been conducting the National Nutrition Survey (NNS) every year since 1946 using almost the same methods. This survey has given accurate information on the daily food consumption and nutrient intake per capita, except for total dietary fiber (TDF). The TDF content of Japanese foods has recently been determined by the AOAC enzymatic-gravimetric method (17), and this data-base has enabled the dietary fiber intake to be precisely calculated.

We evaluated the intake of TDF by Japanese people during the period 1947 to 1987 , namely 41 years. The interrelationships between dietary fiber, other nutrient intake and MCG were determined and analyzed. From the results, we identified the latent period during which nutritional changes exert an effect on the mortality from colon cancer within Japan.

\section{METHODS}

The figures for crude MCC were derived from Vital Statistics of Japan (1947-1987, 14), while nutrition data, except those for TDF, were taken from NNS reports (13).

TDF intake is not directly indicated in NNS reports, so we calculated the figures ourselves. TDF intake per capita was obtained by multiplying the daily intake of each food or each food group shown in NNS reports by the TDF content of various Japanese foods. TDF content data were obtained from the data-base (17) that had been determined by the enzyme-gravimetric method proposed by Prosky et al.

Before attempting a detailed analysis, the figures were studied by an exploratory data analysis involving the nutrient intake and MCC. Two variates that showed a closely nonlinear relationship in a scatter diagram were analyzed by curve- fitting techniques. Two types of models (a linear regression after logarithmic transformation and a nonlinear regression) were then formulated, and the 'goodness of fit' was examined by the residual mean square (RMS) method. This enabled a scatter diagram of the two variates to be drawn. The interrelationship between nutrient intake and MCC was analyzed by Pearson's product moment correlation coefficient (simple correlation coefficient) and assessed by the fit to a linear approximation.

Time-series coefficients of correlation were set up for a zero to 27-year delay in mortality. We calculated the coefficients between MCC and each nutrient intake for each year lag; namely, a 1-year lag shows the coefficient of correlation between the nutrient intake during the period from 1947 to 1986, and MCC during the period from 1948 to 1987.

The calculations were made and the correlation coefficients identified by applying the personal computer program "SAS/INSIGHT, SAS/ STAT" from SAS Institute Japan Inc.

\section{RESULTS}

TDF intake. The annual changes in TDF intake and MCC for Japanese people are shown in Fig. 1. TDF intake per capita decreased rapidly from $27.4 \mathrm{~g}$ in 1947 to $15.8 \mathrm{~g}$ in 1963, and subsequently decreased at a lesser rate to $15.3 \mathrm{~g}$ in 1987. Fat intake increased rapidly from $18.0 \mathrm{~g}$ in 1950 to $56.6 \mathrm{~g}$ in 1987 . Fat energy ratio and fat/TDF intake also increased from $18.9 \%$ to $24.8 \%$ and from 0.47 to 3.69 during same period, respectively.

Coefficient of correlation. Table 1 shows the coefficient of correlation between nutrient intake and MCC. A significant positive correlation was found with fat $(r=0.872)$, protein $(r=0.747)$ and animal protein $(r=0.829)$, while a significant negative correlation was found with TDF $(r=-0.571)$ and carbohydrate $(r=-0.969)$ intake. The energy-adjusted intake of fat was strongly associated with MCC $(r=0.904)$. For the nutrient/TDF intake ratio, a positive correlation was apparent in energy/TDF $(r=0.600)$, protein/TDF $(r=0.736)$, animal protein/TDF $(r=0.838)$ and fat/TDF 


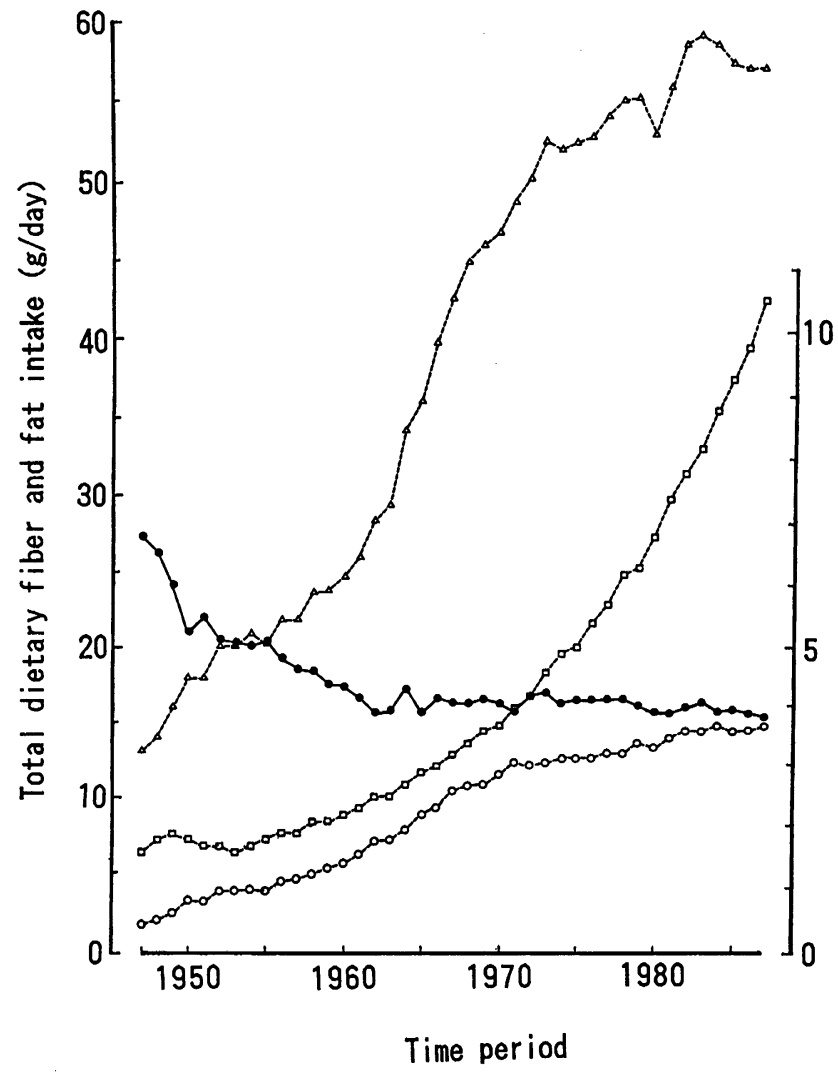

Table 1. Chronological coefficient of correlation between nutrient intake and colon cancer crude mortality in Japan

\begin{tabular}{|c|c|c|c|}
\hline \multirow[b]{2}{*}{ Nutrient } & \multirow{2}{*}{$\begin{array}{c}\text { Coefficient } \\
\text { of } \\
\text { correlation } \\
0 \text { year } \\
n=41\end{array}$} & \multicolumn{2}{|c|}{ Time-series analysis } \\
\hline & & $\begin{array}{c}\text { Time lag } \\
\text { year } \\
{[n]}\end{array}$ & $\begin{array}{c}\text { Maximum } \\
\text { coefficient } \\
\text { of } \\
\text { correlation }\end{array}$ \\
\hline TDF & $-0.571^{*}$ & $24[17]$ & $-0.918^{*}$ \\
\hline Energy & 0.018 & $14[27]$ & 0.907* \\
\hline Carbohydrate & $-0.969 *$ & $6[35]$ & $-0.984 *$ \\
\hline Protein & $0.747 *$ & $14[27]$ & $0.944^{*}$ \\
\hline Animal protein & $0.829 *$ & $14[27]$ & $0.960^{*}$ \\
\hline Fat & $0.872^{*}$ & $16[25]$ & $0.990^{*}$ \\
\hline Fat/energy (\%) & $0.904^{*}$ & $16[25]$ & $0.992 *$ \\
\hline Sucrose & -0.015 & $16[25]$ & $0.792^{*}$ \\
\hline Energy/TDF & $0.560^{*}$ & $24[17]$ & $0.956^{*}$ \\
\hline Carbohydrate/TDF & -0.291 & $24[17]$ & $0.936^{*}$ \\
\hline Protein/TDF & $0.736^{*}$ & $24[17]$ & $0.950 *$ \\
\hline Animal protein/TDF & 0.838* & $14[27]$ & $0.962 *$ \\
\hline $\mathrm{TDF} / \mathrm{fat}$ & $-0.647^{*}$ & $22[19]$ & $-0.870^{*}$ \\
\hline Fat/TDF & $0.878^{*}$ & $16[25]$ & 0.994* \\
\hline Sucrose/TDF & 0.159 & $16[25]$ & $0.893^{*}$ \\
\hline
\end{tabular}

$* p<0.05$.
Fig. 1. Changes in dietary fiber, fat intake and mortality from colon cancer in Japan.

- - TDF intake (g/day); -- $\Delta--$ fat intake (g/day); -- -- fat intake/TDF intake; -- $\square--$ colon cancer crude mortality (no./100,000 people).

$(r=0.878)$, while a negative correlation was identified in TDF/fat $(r=-0.647)$.

Regression analysis. The interrelationship between TDF/fat $(X)$ and MCG $(Y)$ is shown by an exponential model $\left(Y=1308 \mathrm{e}^{-19.04 X}+2.030\right.$, RMS; 0.208). Conversely, the relationship between fat/ TDF $(X)$ and MCC $(Y)$ was applied to a second curve $\left(Y=1.327 X^{2}+3.641 X+4.000, \mathrm{RMS} ; 0.503\right)$.

The interrelationship between MCG and TDF intake is shown by two linear regression lines (Fig. 2). The TDF intake rapidly decreased from $27 \mathrm{~g}$ to $18 \mathrm{~g}$ and, during the same period (from 1947 to 1960), MCC slowly increased. Since 1960, TDF intake has slightly decreased, while MCC has rapidly increased. The same findings are also apparent for fat (Fig. 3), fat energy ratio (Fig. 4) and fat/TDF (Fig. 5). The intersection point between the two regression lines gives fat, fat energy ratio and fat/TDF values of about $50 \mathrm{~g}, 20 \%$ and 3.0 , respectively.

Time-series' coefficient of correlation. Figure 6 and Table 1 show changes in the time-series coeffi- 


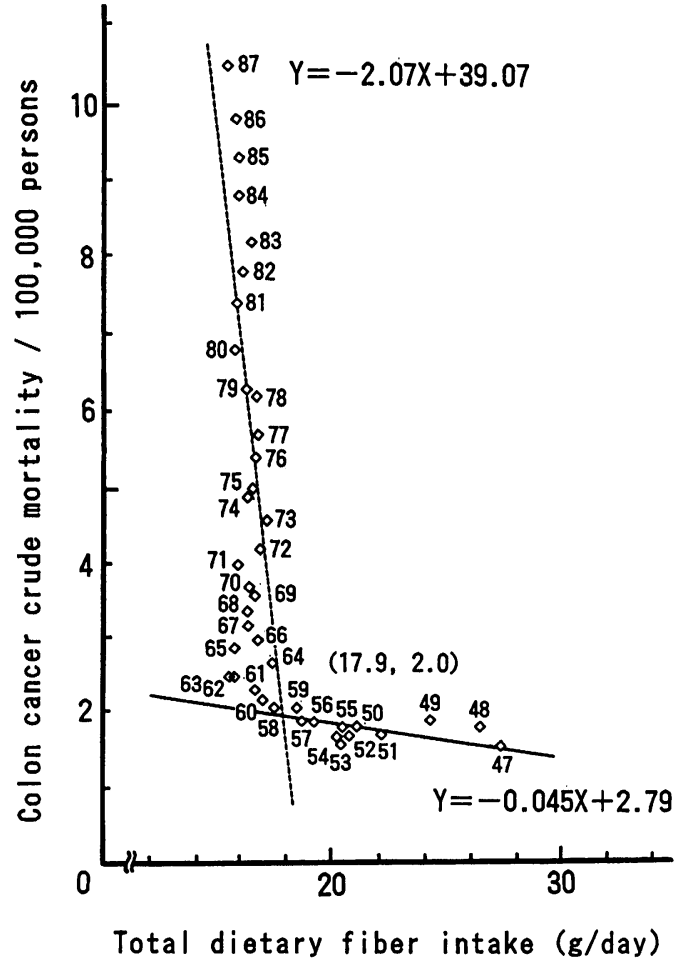

Fig. 2. Regression lines for mortality from colon cancer and dietary fiber intake.

* Numbers show the years.

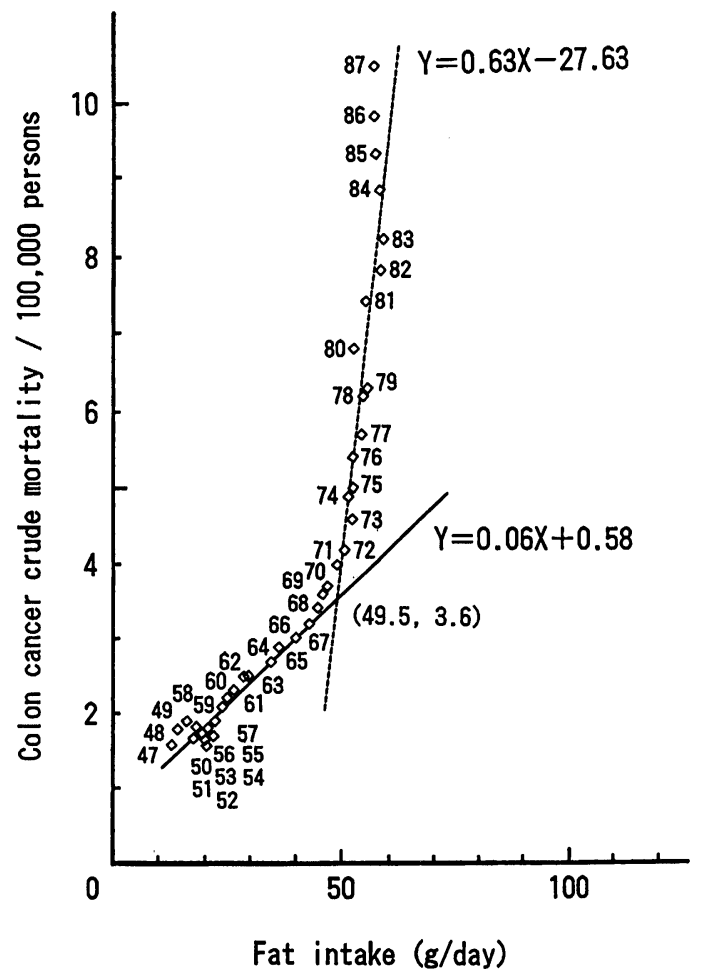

Fig. 3. Regression lines for mortality from colon cancer and fat intake.

* Numbers show the years.

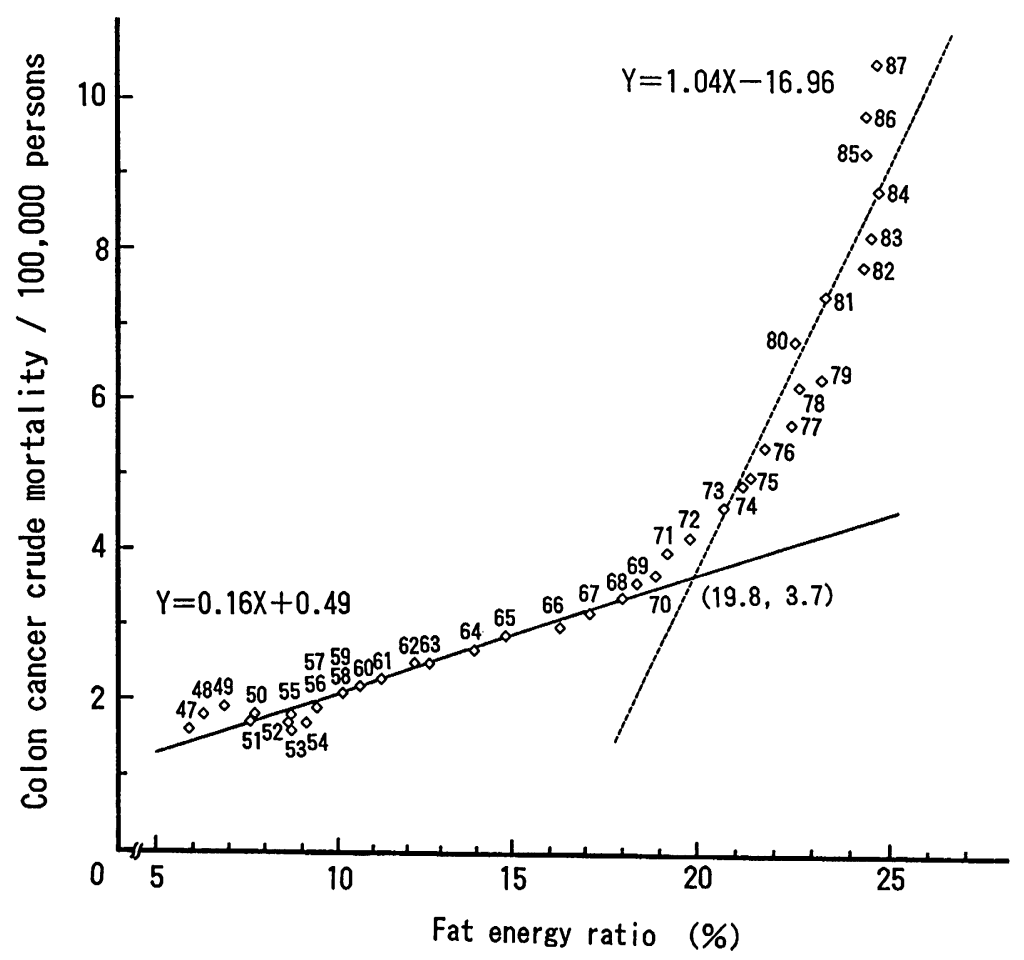

Fig. 4. Regression lines for mortality from colon cancer and fat energy ratio (\%).

* Numbers show the years. 


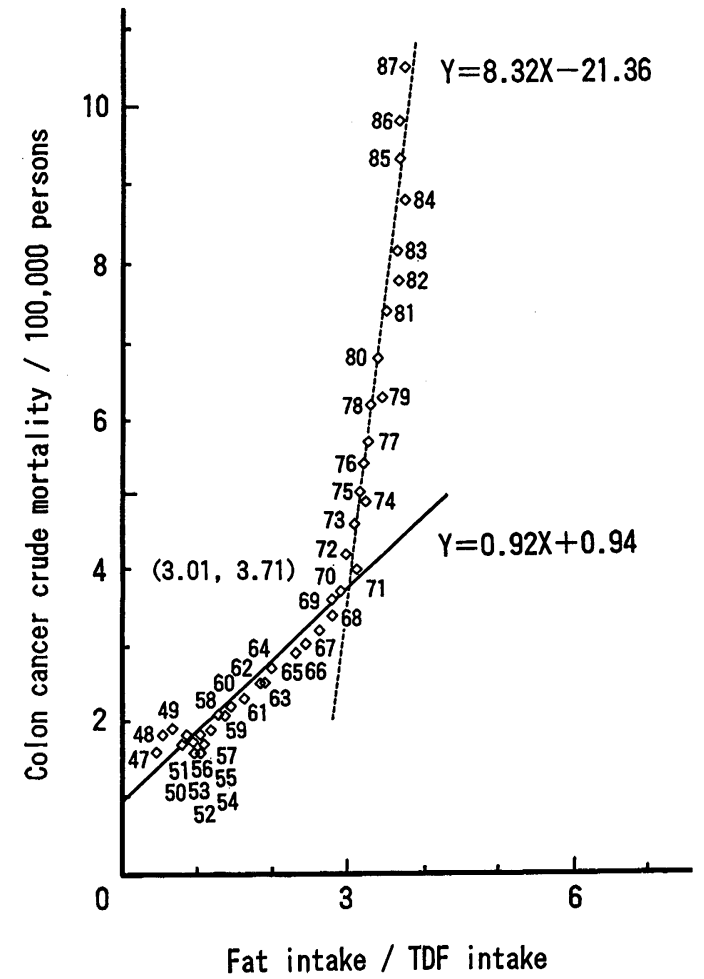

Fig. 5. Regression lines for crude mortality from colon cancer and fat intake/TDF intake.

* Numbers show the years.

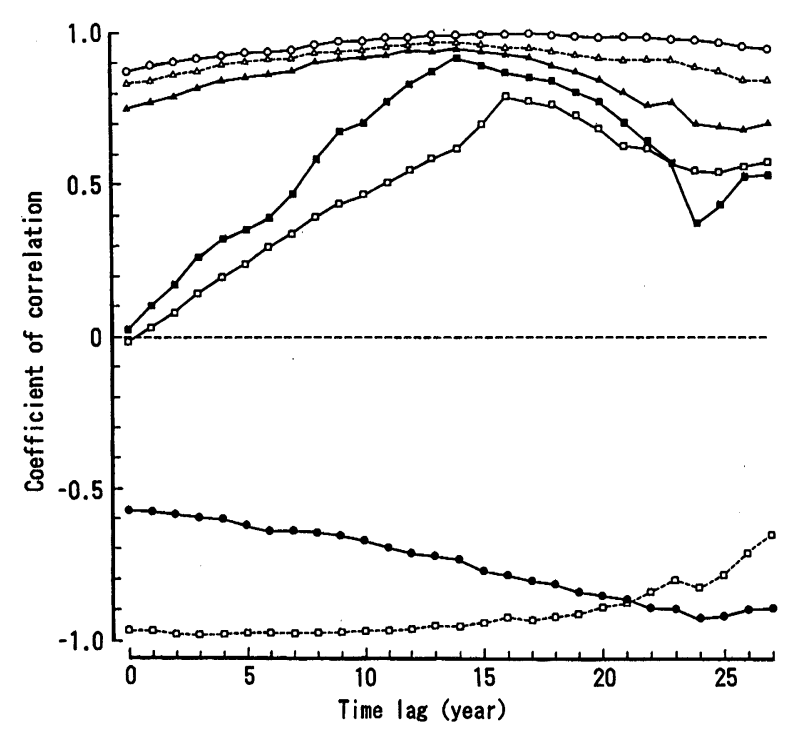

Fig. 6. Changes in the coefficient of correlation between nutrient intake and mortality from colon cancer in Japan (1).

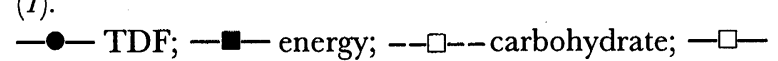
sucrose; -A-protein; -- --- animal protein; $-\mathrm{O}-$ fat.

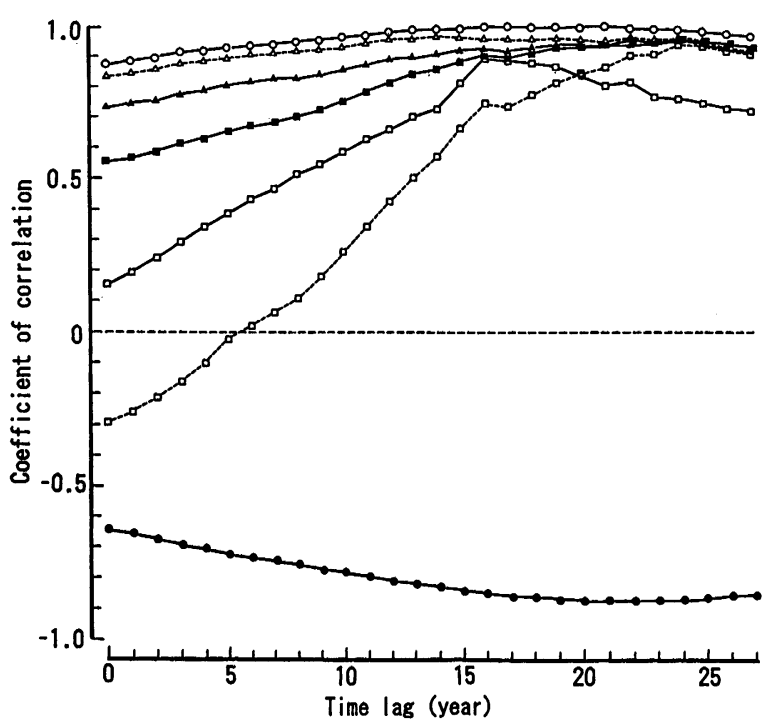

Fig. 7. Changes in the coefficient of correlation between nutrient intake and mortality from colon cancer in Japan (2).

- - Energy/TDF; -- $\square--$ carbohydrate/TDF; - $\square-$ sucrose/TDF; -A- protein/TDF; $--\Delta--$ animal protein/TDF; —O- fat/TDF; -๑-TDF/fat.

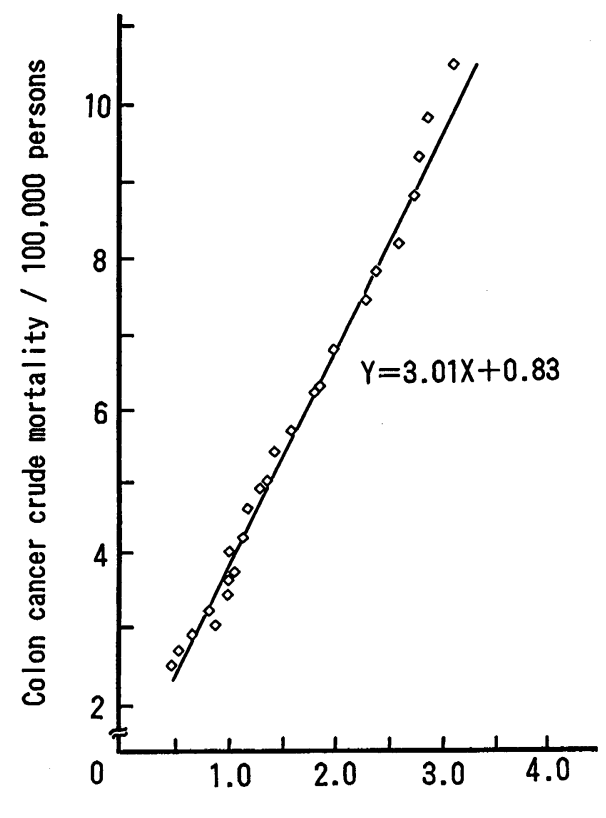

Fat intake / TDF intake

Fig. 8. A regression line for crude mortality from colon cancer and fat intake/TDF intake with a 16-year delay. 
cient of correlation between MCC and the timelag intake of each nutrient. These coefficients of correlation changed and reached a maximum value with increasing time lag. A positive correlation was seen with energy, fat, fat/energy, protein and animal protein. The fat or fat energy ratio reached its maximum correlation after a 16-year delay, while animal protein showed a maximum correlation after a 14-year delay. The maximum negative correlation value between TDF and MCC was -0.918 after a 24-year lag. The maximum correlation for the nutrient/TDF intake was found within a 14- to 24-year delay (Fig. 7). The relationship between fat/TDF and crude mortality had the highest positive correlation after a 16-year delay (Fig. 8, $r=-0.994$ ).

\section{DISCUSSION}

We evaluated the annual intake of TDF by Japanese people during a 41-year period. Our results indicate that there has been a rapid decrease during the period from 1947 to 1963, and a decreasing trend of TDF intake during the period from 1964 to 1987. Although not indicated in this paper, the supply sources of TDF varied year by year. Nishimune et al (17) calculated the TDF intake by Japanese people, using NNS reports and a TDF table, every five years during the period from 1951 to 1990 . Our data showed the same trends as indicated by their findings. As our TDF data depended only on the values from vegetable foods, the recent per capita intake that we calculated had decreased to $15.0 \mathrm{~g}$ per day by 1993. The value for TDF from animal foods is about $1 \mathrm{~g}$ per day per capita (17), so the per capita daily intake of TDF from all food items would be about $16 \mathrm{~g}$. It is well known that physiological differences in the intestine occur due to the different solubilities of different types of dietary fiber (18). The intake ratio of insoluble to soluble dietary fiber was estimated at about $4: 1$ in Japanese (22). However, the effects of each dietary fiber fraction on human colon cancer are still unknown at the present time.

We then identified the amount of time needed for nutritional changes to exert an effect on MCC in Japan. In inter-country studies $(7,12)$, the association between colon cancer incidence and mortality rate versus the estimated national average consumption of fat and meat was remarkably strong. However, TDF intake seemed to be equivocally associated with colon cancer risk. In intracountry epidemiological studies, no reliable reports have been presented that were based on annual changes of both nutrition intake and mortality in Japan during the prolonged period used in this study.

Present data indicate that MCC has a strong positive association with fat, the maximum correlation being after a 16-year delay. The correlation analysis of international data by Liu et al (12) led to the conclusion that fat intake was significantly associated with colon cancer after about a 10-year lag. Willett (23) showed that an increasing proportion of MCC with increased fat intake had a 15-year lag in Japan during the period from 1955 and 1985. The present data strongly indicate that the increase in fat intake is positively associated with the risk of colon cancer after a 10-16-year lag.

The results of this study indicate that MCC has a strong inverse correlation with TDF after more than a 16-year lag, and a maximum correlation after a 24-year lag. Greenwald et al (7) assessed a possible association between dietary fiber and colon cancer, but the time lag is not clear. Heilbrun et al (9) reported a significant negative association between TDF and colon cancer risk in men with a low fat intake $(<61 \mathrm{~g} /$ day $)$, after a follow-up period of over 16 years in American Japanese. TDF requires considerable time to exert an effect on mortality. We should give full consideration to the time lag, because it takes a considerable time before nutrients increase the MCC risk. Present data support such a time-lag connection between colon cancer and TDF intake. When the daily intake of TDF was less than $18 \mathrm{~g}$, colon cancer mortality rapidly increased, so the present intake (16-17 g/day) may not be enough.

In addition, fat/TDF showed the most striking correlation with MCC among all nutritional 
parameters. To explain this relationship, a highfat diet changes the composition of bile acids, and also modifies the activity of gut microflora that produce $\beta$-glucuronidase $(10,18,19)$. On the other hand, a high intake of certain types of dietary fiber not only leads to an increase in stool bulk, but also increases bacterial fermentation and the production of short-chain fatty acids that are thought to lower the $\mathrm{pH}$ value $(2,5,18)$.

TDF intake in Japan is lower than that in Europe and America (1), although there are differences in sampling and estimating methods. However, we can say that the recent intake of fat in Japan is about $60 \mathrm{~g}$ per capita per day. This level is very low compared with the values for Western Europe and North America and results in lower fat/TDF in Japan. This finding may explain the lower incidence of colon cancer in Japan. When fat/TDF is more than 3.0, MCG rapidly increases, and this point is thus a significant nutritional criterion. The above-mentioned findings imply that TDF intake should be more than $20 \mathrm{~g}$ per day. Dales et al (6) reported that the relative risk of $\mathrm{MCC}$ for a high-fat, low-fiber diet to be 2.7 times more than that for a low-fat, high-fiber diet. However, with a high dietary intake of fat, dietary calcium within the gut may form an insoluble soap with fatty acids and fecal sterols to reduce the carcinogenicity of certain substances in the colon (16).

Another significant positive factor was found to be protein, and especially animal protein. Protein metabolites, such as ammonia, tryptophan, $\mathcal{N}$-nitroso-compounds and heterocyclic amines that are produced by cooking protein-containing foods, are thought to have carcinogenic properties for the human large intestine $(4,15)$. Suzuki et al (21) reported that the levels of volatile nitrosoamines in human feces were markedly increased in Japanese people consuming a Western diet when compared with Japanese eating a traditional Japanese diet. We should also note the strong correlation between animal protein and fat intake. It is possible that this dietary protein exerts an indirect influence on MCC, and more careful consideration should be given to these factors.
A considerable negative correlation has been indicated between carbohydrate and MCC, although no clear explanation of this phenomenon is apparent at present. It is still unclear that a strong negative correlation indicates no direct causal relationship between two parameters. One possible explanation may be that carbohydrate includes many components such as TDF, starches and resistant starch that are related to this disease.

Although further investigation is necessary, it is suggested that the cause of the increased MCC in Japan is positively related to the increased intake of fat with a 16-year delay. In addition, the decrease in TDF intake has accelerated MCC after a delay of 24 years. The importance of fat/ TDF as a nutritional criterion for the incidence of colon cancer may need to be better recognized.

\section{REFERENCES}

(I) Bright-See E: Estimation of dietary fiber supply. Am J Clin Nutr 41: 824-826, 1985

(2) Burkitt DP and Trowell HC (eds): Refined Carbohydrate Foods and Disease, Academic Press, London, 1975

(3) Carroll KK: Lipids and Cancer. In Nutrition and Disease Update-Cancer, Carroll KK and Kritchevsky D (eds), AOCS Press, Champaign. 1994, p. 235296

(4) Cummings JH, Hill MJ, Bone ES, Branch WJ and Jenkins DJA: The effect of meat protein and dietary fiber on colonic function and metabolism. II. Bacterial metabolites in feces and urine. Am J Clin Nutr 32: 2094-2101, 1979

(5) Cummings JH, Pomare EW, Bramch WJ, Naylor CPE and Macfarlane GT: Short chain fatty acids in human large intestine, portal, hepatic and venous blood. Gut 28: 1221-1227, 1987

(6) Dales LG, Friedman GD, Ury HK, Grossman S and Williams SR: A case-control study of relationships of diet and other traits to colorectal cancer in American blacks. Am J Epidemiol 109: 132-144, 1979

(7) Greenwald MD, Lanza E and Eddy GA: Dietary fiber in the reduction of colon cancer risk. J Am Dietetic Assoc 87: 1178-1188, 1987

(8) Haenszel W, Berg JW, Segi M, Kurihara M and Locke FB: Large-bowel cancer in Hawaiian Japanese. J Natl Cancer Inst 51: 1765-1179, 1973

(9) Heilbrun LK, Nomura A, Hankin JH and Stemmermann GN: Diet and colorectal cancer with special 
reference to fiber intake. Int J Cancer 44: 1-6, 1989

(10) Hill MJ and Crowther JS: Bacteria and etiology of cancer of large bowel. Lancet 16: 95-100, 1971

(11) Lee JAH: Recent trends of large bowel cancer in Japan compared to United States and England and Wales. Int J Epidemiol 5: 187-194, 1976

(12) Liu K, Stamler J, Moss D, Garside D, Persky V and Soltero I: Dietary cholesterol, fat, and fibre and colon-cancer mortality. Lancet 13: 782-785, 1979

(13) Ministry of Health and Welfare in Japan: The national nutrition survey report. Daiichi Publishing Co, Tokyo, 1947-1987 (in Japanese)

(14) Ministry of Health and Welfare in Japan: Vital Statistics of Japan, MHWJ, Tokyo, 1947-1987 (in Japanese)

(15) Nagao $M$ and Sugimura T: Carcinogenic factors in food with relevance to colon cancer development. Mutat Res 290: 43-51, 1993

(10) Newmark HL, Wargovich MJ and Bruce WR: Colon cancer and dietary fat, phosphate, and calcium: a hypothesis. J Natl Cancer Inst 72: 1323-1325, 1984
(17) Nishimune T, Sumimoto T, Yakushiji T, Kunita N, Ichikawa $T$, Doguchi $M$ and Nakahara S: Determination of total dietary fiber in Japanese foods. J Assoc Off Anal Chem 74: 350-359, 1991

(18) Pilch SM (ed): Physiological effects and health consequences of dietary fiber. FDA, Washington, 1987

(19) Reddy BS: Diet and excretion of bile acids. Cancer Res 41: 3766-3768, 1981

(20) Stemmermann GN, Mandel M and Mower HF: Colon cancer: Its precursors and companions in Hawaii Japanese. J Natl Inst Monogr 53: 175-179, 1979

(21) Suzuki $\mathrm{K}$ and Mituoka T: Increase in fecal nitrosamines in Japanese individual given a Western diet. Nature 294: 453-456, 1981

(22) Watanabe T, Kuga T and Takai Y: Intake of water soluble, water insoluble and total dietary fibers by the Japanese. Jpn J Nutr 52: 119-129, 1994 (in Japanese)

(23) Willett W: The search for the causes of breast and colon cancer. Nature 338: 389-393, 1989 